\title{
A CONTINUIDADE COMO CONCEITO DO PODER
}

\section{Davi Oliveira da Silva ${ }^{1}$}

Resenha de: HAN, Byung-Chul. O que é o poder? Tradução de Gabriel Salvi Philipson. Petrópolis, Rio de Janeiro: Editora Vozes, 2019.

A obra O que é o Poder? de Byung-Chul Han, publicada no Brasil em 2019, tem como pretensão responder adequadamente à pergunta título, pois, segundo a compreensão do autor, ao redor do poder ronda um caos teórico, o que dificulta estabelecer um consenso a respeito do que consistiria o poder, seu modo de ser e de funcionar. Han entende que o poder é um fenômeno demasiadamente complexo e, nesse sentido, para ter uma compreensão que não falte com algum modo de representação ou de aparição do poder, pretende formular um conceito móvel, capaz de adaptar-se a qualquer estrutura de poder possível. Podemos dizer que definir o campo de atuação do poder, separando-o expressamente da violência, é um dos desafios que Han se propôs ao desenvolver sua tese.

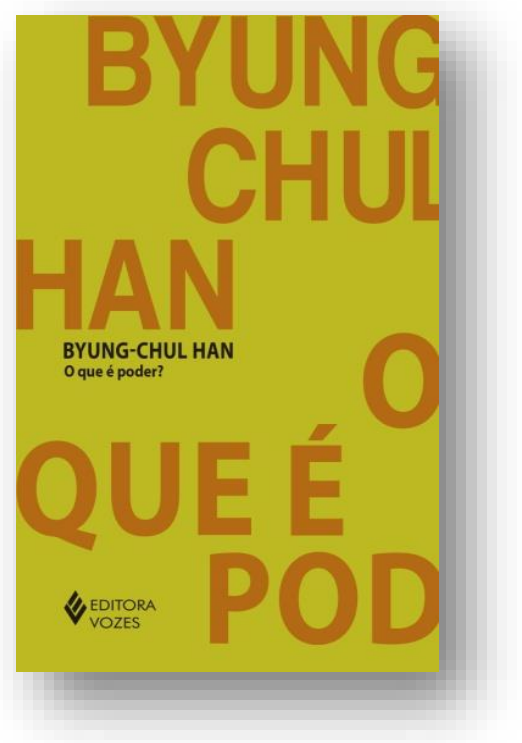

De inspiração foucaultiana, Byung-Chul Han, quer evitar a afirmação de que o poder estaria unilateralmente ao lado da coerção, como uma luta de forças antagônicas, ou do consenso, pelo lado habermisiano da comunicação. A ideia seria encontrar um conceito que não elimine sua ocorrência, tanto por via coercitiva, como consensual, mas que não seja conceituado como tal. Han expande o olhar nessa querela, e procura mostrar que o fenômeno do poder excede qualquer tentativa de mitigar sua complexidade. $\mathrm{Na}$ medida em que o conceito de poder é central na obra, o autor organiza seus capítulos de tal modo a reforçar a sua tese.

No primeiro capítulo, Lógica do poder, Han aborda a relação entre o ego e o alter, demonstrando como se efetua esta relação para além da causalidade atestada por algumas concepções de poder. Para Han essa relação deve ser descrita pela ideia de continuidade.

No segundo capítulo, Semântica do poder, temos a vinculação do conceito do poder com a criação de sentido. O ego tem sua continuidade possibilitada sobre o alter ao fazer surgir um horizonte de significação. Deste modo, o poder atuaria ao fazer circular a representação e o sentido, forçando hábitos, que permitem que ele se oculte na cotidianidade.

No terceiro capítulo, Metafísica do poder, o argumento de retorno-a-si do poder é abordado utilizando conceitos como o de Hegel, do espírito absoluto, e Heidegger na ontologia do Ser. O poder lança-se, então, na exterioridade; contudo, retorna a si ao forçar sua subjetividade no outro, retornando ao interno no externo.

${ }^{1}$ Professor Licenciado em Filosofia pela Universidade do Estado do Amapá. Pesquisador nas áreas de epistemologia, filosofia política e literatura \& filosofia. E-mail: davi.olly3@gmail.com. Orcid: http://orcid.org/0000-0002-5398-4133 
No quarto capítulo, Política do poder, o autor desenvolve a ideia do espaço-poder. O poder, ao continuar-se na exterioridade, cria espaços de atuação política. Por isso, ao poderoso, o sentimento de ganho de poder é sentido como ganho de espaço. Han também afirma que o poder não pode ser desvinculado de uma qualidade estratégico-política, que lhe é inerente.

No quinto e último capítulo, Ética do poder, o autor ocupa-se das ideias de lugar e de liberdade. O poder, assim como o lugar, reúne tudo em um, em um centro. De outro modo, ao falar da liberdade, não discorda de que, para existir relação de poder deve existir liberdade, nem que seja de um modo mitigado.

\section{A CONTINUIDADE ENTRE EGO E ALTER}

"O poder cria uma continuidade" (HAN, 2019, p.144). "O poder é um fenômeno da continuidade" (idem, p.18). Nessas afirmações, Han demonstra o que, para ele, consiste o poder. Sem continuidade, não existe poder. Pois a continuidade é o que forma as estruturas de poder. Logo, a continuidade está ligada à própria gênese do poder.

Han se distancia totalmente das concepções de poder que compreendem este como uma causalidade, ou seja, como se o subordinado fosse afetado causalmente pela vontade do subordinador. Nesta visão, ego e alter estão ligados de modo linear a uma atuação causal, na qual o ego, do alto do seu poder, se direciona ao alter forçando sua vontade; e o alter receberia, passivamente, a ordem do ego. Para Han, no entanto, essa interpretação não é adequada à complexidade do fenômeno do poder. Ela ignora, por exemplo, a parte ativa dos agentes do poder, de ambos os lados, do subordinador e do subordinado, que Foucault já atestava na sua ideia de funcionamento do poder.

A relação entre ego e alter está baseada em uma relação de continuidade. O desejo do ego é de se continuar no outro, pois a vontade de poder está justamente baseada nessa possibilidade de o ego propagar-se no alter: quando essa continuidade é possível, começa o poder. O ego depende, então, do alter para ter a sua continuidade.

Deste modo, como afirma Han, o alter não sofre a vontade do ego como algo alheio a si, como na relação de causa e efeito. No entanto, de modo ativo, se projeta na vontade do ego. O ego, para possuir poder, não pode agir sem levar em consideração o alter, pois, desta forma, ignorando o alter, perde em domínio de poder. Quando o ego não encontra colhida no alter, seu poder é questionado, ou mesmo, já se encontra em derrocada.

Podemos afirmar, então, que o poder depende irrevogavelmente dessa relação. Quanto mais poderoso deseja ser o ego, mais ele tem que aumentar a sua continuidade perante o alter. Note que sem alter não existe poder. Logo, um poder que exclua a existência do outro, também tem sua existência finda. O modo de existência e de realização do ego é ser no alter.

$\mathrm{O}$ ego deve encontrar um modo de se continuar no alter. Isso pode acontecer de diversas maneiras, visto a complexidade do poder. Han não exclui da continuidade do poder a possibilidade de ela acontecer por via coercitiva. Apesar dele deixar claro que a violência e o poder são fenômenos opostos, não nega que ela venha a ser utilizada pelo ego. O poderoso pode utilizar-se, como muitas vezes se utiliza, de métodos violentos, para ter efetivada sua continuidade no outro. No entanto, quando o ego tem necessidade de se afirmar através da violência, ou de modo coercitivo, é porque tem pouco ou quase nenhum poder sobre o alter. Uma concepção de poder que se baseia apenas no seu modo negativo é uma visão limitada, pois diminui a complexidade do poder. Essa visão enxerga o alter passivamente, sem muita participação na 
estrutura do poder. Quando o ego consegue ter sua vontade acolhida pelo alter sem que este a rejeite, ganha em domínio e força. Assim, o poder funciona de tal forma que o alter se projeta na vontade do ego, não como vontade do poderoso, mas como seu próprio desejo, como sua escolha e decisão.

Uma forma de poder absoluto seria aquela em que a continuidade do ego não encontra barreira para se realizar no alter, ou melhor, um poder absoluto não encontra algo que lhe resista. Nesse ponto, Han se diferencia de Foucault, já que este acredita que não existe poder sem forças de resistência. Contrariamente, Han afirma que o poder pode acontecer sem que as encontre, mas, nesse caso, teria que ocorrer com uma continuidade sem limites. Um poder sem resistência demonstra a estabilidade atingida por um determinado domínio.

Quando o poder precisa dar mostras de si é porque é fraco. No entanto, quando acontece silenciosamente, seja disfarçado nas engrenagens sociais, ou mesmo no hábito, é mais robusto e eficaz. Astuto é o poder que se disfarça no cotidiano, que cria hábitos e costumes, que os subordinados recebem como natural e autoevidente. Desta maneira, o poder que deseja atingir um espaço grande de domínio precisa atuar através da criação de um horizonte de sentido.

Podemos compreender das palavras de Han que o poder não é apenas negativo, mas igualmente positivo. O poder, mesmo na sua eloquência, não está determinado na negação do outro, mas na afirmação de si no outro. Ego e alter são co-partícipes da estrutura do poder. O poder retira do alter não o seu não amedrontado, mas o seu sim entusiástico, cheio de excitação e subserviência. Pois, bem lembra Han, que o poder não apenas destrói, mas deixa viver.

\section{A CONTINUIDADE DO SELF}

A continuidade é a capacidade de ir-além-de-si. No entanto, o poder não se esgota nesta atividade, pois, se assim fosse, o ego se perderia no outro, no que é exterior a si. Diferentemente, a continuidade que Han atribui ao poder se caracteriza na saída e no retorno-a-si. O ego vai além-de-si, mas retorna-a-si no outro. Não perde a si mesmo, mas afirma-se, na sua própria subjetividade e desejo. A vontade de poder quer ir além de si, deseja continuar-se no outro, permitindo que sua subjetividade se expanda no outro. Assim, o fora do poder não deixa de ser dentro, ou seja, ele mesmo.

Poder é, então, essa capacidade de ir-além-de-si estando junto de si. Ao se encaminhar para o exterior, o ego leva sua subjetividade para o outro e repousa nele, ali tem sua morada. O poder cria seu self, e essa é sua característica principal. O poder sempre será esse modo de continuidade que se funda ao criar seu self. Pois a vontade de poder é nada menos que vontade de si. O poder é certamente a soberania do self; é a vontade do poderoso que não se quebra diante da vontade do outro, antes, tem sua subjetividade alcançada na alma do subordinado. Sem continuidade do self não há poder, pois sem vontade de si não existe estrutura de poder.

Han enfatiza que o poder nunca se abstém de si, mas procura estar em si em toda parte. Deste modo, o poder é um fenômeno da interioridade, enxergando o fora como dentro. Ele se projeta na exterioridade como forma de ser-si-mesmo. Logo, o poder é o fenômeno do eu. O soberano projeta-se para fora na tentativa de alargar seu self, criando uma estrutura de poder que não deixa de responder à sua própria subjetividade. Deste modo, um domínio diz respeito ao self do soberano.

A continuidade do self, ao projetar-se no exterior, cria um espaço-poder, ou seja, a subjetividade do poderoso ao preencher o exterior consigo, aumenta seu espaço de poder. Deste 
modo, para Han, o poder também será um fenômeno espacial. A continuidade, sendo constitutiva de toda forma de poder, ao possibilitar a espacialização do self, torna a criação de espaços uma das suas características. Essa espacialização do poder é a configuração autêntica da ação política.

Um poder sem lugar não é poder, pois está em lugar nenhum, está isolado. Lembremos a afirmação de Foucault para o qual só há poder quando existe certa relação entre indivíduos, ou de Hannah Arendt que compreende que o poder surge quando os homens começam a agir entre si. Assim, não há poder no isolamento. O poder solitário gera violência. É da lógica do poder ir-além-de-si. É a continuidade do self que cria esse espaço de atuação política do poder.

A ideia de lugar é utilizada por Han para caracterizar o poder como “ipsocentrado”. O lugar recolhe tudo para si, reúne tudo em um e, do mesmo modo opera o poder. Ele é centralizador. Ele reúne o que lhe é exterior em um todo orgânico, que não deixa de ser a sua própria subjetividade. É basilar para o poder esse centro, pois quando o poder reúne tudo como seu "eu mesmo" tem a possibilidade de retorno-a-si. No entanto, essa vontade de si contínua dificulta um tratamento ético do poder, ou mesmo, de vinculá-lo ao conceito de justiça. Pois a ética e a justiça dizem respeito ao outro, ao olhar o outro, em sua alteridade, exigindo a suspensão do self.

De outro modo, Han, ao não eliminar a coerção do fenômeno do poder aproxima esta da violência, pois ambas serão uma técnica de subjugação, o que vai diferenciá-las será a possibilidade de mediação.

\section{A CONTINUIDADE NA MEDIAÇÃO}

A passagem da vontade do ego ao alter, evidenciada pela continuidade do self, deve acontecer de tal modo que o alter a receba não como hiato entre as partes, mas antes o próprio alter deve renunciar a sua vontade em detrimento daquela exercida pelo ego. Contudo, se o contrário acontecer, se o alter não for ele mesmo um reflexo do poder do ego, não há retorno-a-si do ego, logo não há relação de poder. É da lógica do poder esse funcionamento contínuo da continuidade do self. O ego, apesar da presença do outro, suspende aquela alteridade outra, e habita o mundo como aparência subjetivada do seu "eu mesmo". A passagem ao outro não deixa de ser uma passagem a si. $\mathrm{O}$ poderoso anseia sua continuidade.

Deste modo, o alter, ao ser atingido pela vontade do ego, não deve reconhecê-la como diferente de si. Contrariamente, o alter renuncia sua alteridade, seu desejo de si, e projeta-se na vontade do poderoso. O poder gera uma diminuição da distância entre ego e alter.

A decisão do ego não deve ocorrer de modo alheio para o alter, mas antes deve ser querida por este, pois no poder o alter estar em um espaço que não deixa de ser a subjetividade do poderoso. O alter não está no espaço do poder independente do seu desejo de estar ali, ao contrário, ali está o seu desejo, seu sentido, seu modo de ser. É em liberdade que o alter se projeta na vontade do poderoso. Assim, o poder autêntico baseia-se na mediação entre ego e alter. É inerente ao poder estruturas de medição. Sem medição não há poder, apenas a violência desnudada.

Podemos afirmar que, na interpretação sobre o funcionamento do poder proposto por Han, a mediação é um ponto importante, pois sem a mediação o poder seria violência e, neste caso, a mediação é justamente o que difere a atuação do poder do fenômeno da violência. A mediação é o que permite que o alter aceite subservientemente a vontade do ego. 
No entanto, lembremos que a continuidade do self pode ocorrer de modo coercitivo, ela pode ser forçada. Mas quando acontece dessa forma é porque houve pouca mediação. Um poder pobre de mediação possui igualmente pouco espaço de atuação. O poder, quando não mediado, é diminuto, pois o seu corpo recolhe-se na sua interioridade. Deste modo, o poder está longe de ser fruto apenas da coerção, pelo contrário, sua força está no seu poder de mediação. A medição, ao transformar a vontade do poderoso na vontade do subordinado, gera liberdade. Quando a medição entre ego e alter for grande, ambos usufruem dessa liberdade.

Em Han, assim como em Foucault, para existir poder deve existir liberdade. Contrariamente, as relações de poder estão saturadas quando a liberdade, gerada pela medição, é restrita. No entanto, Han será menos rigoroso a respeito da liberdade se compararmos a sua concepção com a de Foucault. Este, ao falar da relação entre poder e liberdade, afirma que uma relação como a escravidão, que nega qualquer possibilidade de liberdade ou de fuga, não é uma relação de poder. Para Han, ao contrário, a mínima possibilidade de liberdade permite que ainda exista poder, ainda que escasso. Neste caso, a possibilidade de o escravo de dizer "não" à vontade do poderoso é um modo de liberdade. Mesmo que pequeno esse "não" interrompe a mediação do poder entre ego e alter. Por isso mesmo, o poder é caracterizado não pelo seu não, mas pela possibilidade do sim.

Pouca mediação desdobra-se em coerção, nenhuma mediação em violência. A violência, diferentemente do poder, quebra a continuidade do self, destrói o alter, isola o ego. A violência não é poder, pois aniquila o outro, encerra com os espaços de ação política. Um poder violento é, assim, contraditório ao violar seu modo de ser. Como a violência é aniquilação, ela não estrutura, não centraliza, não organiza, ela é vazia de sentido.

O poder é essa relação entre ego e alter, o eu e o outro, a interioridade e a exterioridade. O poder comunga sentido, institui espaços, coordenada ações. Desta maneira, o poder não atua na violência, e mesmo quando se utiliza dela, é para gerar sentido, forçar simbologias, extrair rituais. Não é assim que o poder régio funciona na antiguidade, como atesta Foucault? Ao forçar o súdito à violência da espada, lhe retiram sinais, sinais estes que são representativos da própria subjetividade do rei.

A visão arcaica de poder é pobre de mediação, logo é violenta. O poder arcaico ao destruir seu oponente na intenção de possuir seu noma, encerra com a relação de poder. Contudo, poder e violência são modos de subjugação, pois se direcionam sobre a alteridade do outro, a diferença reside no fato de que em uma relação de poder a alteridade é suspendida, ou diminuída, na vontade do poderoso. Na violência, a alteridade é destruída no aniquilamento do outro.

\section{QUESTÕES FINAIS}

O conceito de poder que Byung-Chul Han desenvolve na obra O que é poder? aborda uma estrutura que tem potencial de ser transportado para qualquer aparição do poder. Han defende que o poder não pode ser diminuído nas suas formas de coerção, ou na perspectiva de um consenso. Tanto a coerção, como o consenso, são modos de aparição do poder; apesar disso, nenhum aparece em sua forma pura, no entanto, um poder que se funda na mediação das suas partes antagônicas consegue uma estabilização contínua.

Partindo de conceitos já trabalhados a partir de filósofos que abordaram a questão do poder, Han desenvolve sua tese, atento às transformações que se passam o mundo 
contemporâneo, pois ele procura adequá-los a um funcionamento de poder que permita responder às questões prementes de nosso tempo. Neste caso, Han salienta a passagem de um poder que se utiliza nem tanto de uma base negativa, para um em que a positividade é seu fundamento. Para ele, vivemos em uma sociedade que aspira o desempenho, a produtividade, ou seja, um excesso de positividade.

Cabe observar, assim, que Han ressalta a importância da mediação como característica ao poder, para distingui-lo do fenômeno da violência. Para o filósofo coreano é plausivelmente possível cogitar a existência de um poder que não se enverede para os rumos da violência. Deste modo, é fundamental diferenciar estes dois fenômenos, para que compreendamos as peculiaridades explícitas nas intencionalidades específicas de ambas.

\section{REFERÊNCIAS}

FOUCAULT, Michel. O sujeito e o poder. In: DREYFUS, Humbert L; RABINOW, Paul. Michel Foucault, uma trajetória Filosófica: Para além do estruturalismo e hermenêutica. Tradução de Vera Porto Carrero. Rio de Janeiro: Forense Universitária, 1995.

HAN, Byung-Chul. Topologia da Violência. Tradução de Enio Paulo Giachini. Petrópolis, Rio de Janeiro: Editora Vozes, 2017. 